\title{
Role of Biological Sex in the Cardiovascular-Gut Microbiome Axis
}

\author{
Shuangyue $\mathrm{Li}^{1}$ and Georgios Kararigas ${ }^{2 *}$ \\ ${ }^{1}$ State Key Laboratory of Cardiovascular Diseases, National Center for Cardiovascular Diseases, Fuwai Hospital, Chinese \\ Academy of Medical Sciences and Peking Union Medical College, Beijing, China, ${ }^{2}$ Department of Physiology, Faculty of \\ Medicine, University of Iceland, Reykjavik, Iceland
}

There has been a recent, unprecedented interest in the role of gut microbiota in host health and disease. Technological advances have dramatically expanded our knowledge of the gut microbiome. Increasing evidence has indicated a strong link between gut microbiota and the development of cardiovascular diseases (CVD). In the present article, we discuss the contribution of gut microbiota in the development and progression of CVD. We further discuss how the gut microbiome may differ between the sexes and how it may be influenced by sex hormones. We put forward that regulation of microbial composition and function by sex might lead to sex-biased disease susceptibility, thereby offering a mechanistic insight into sex differences in CVD. A better understanding of this could identify novel targets, ultimately contributing to the development of innovative

OPEN ACCESS

Edited by:

Saskia C. A. De Jager,

Utrecht University, Netherlands

Reviewed by:

Benedetta Izzi,

Mediterranean Neurological Institute

Neuromed (IRCCS), Italy

Susana Novella,

University of Valencia, Spain

*Correspondence:

Georgios Kararigas

georgekararigas@gmail.com

Specialty section:

This article was submitted to Sex and Gender in Cardiovascular

Medicine,

a section of the journal

Frontiers in Cardiovascular Medicine

Received: 17 August 2021 Accepted: 16 December 2021

Published: 10 January 2022

Citation:

Li S and Kararigas G (2022) Role of Biological Sex in the Cardiovascular-Gut Microbiome Axis. Front. Cardiovasc. Med. 8:759735. doi: 10.3389/fcrm.2021.759735 preventive, diagnostic and therapeutic strategies for men and women.

Keywords: cardiovascular, gut microbiota, heart failure, sex differences, vasculature

\section{INTRODUCTION}

Despite advances in prevention strategies, as well as pharmacological and technology-based cardiovascular (CV) therapies, CV diseases (CVD) remain a major health burden, as they are the leading cause of morbidity and mortality (1). Notably, the development, progression and outcome of CVD, as well as the response to CV pharmacotherapies differ significantly between the sexes $(2,3)$. However, the contributing mechanisms are incompletely understood. Important modifiable risk factors for CVD include diabetes, hyperlipidemia, hypertension and obesity (4). These factors are linked to nutrition, and interventions aiming at modifying dietary patterns are expected to be beneficial in their successful management and the prevention of CVD (5-8). Interestingly, the old Chinese proverb "disease enters from the mouth" appears to be of relevance. The gut microbiome and its involvement in the development and outcome of CVD have recently attracted wide interest $(9,10)$, thereby emerging as a key modulator of CV health and disease. Of note, there are several factors that can alter the gut microbiome in a sex-specific manner (Figure 1A). In the present article, we highlight how the gut microbiome can affect the CV system and we explore how biological sex and sex hormones may influence this interaction, thereby contributing to sex differences in CVD. It is not our purpose to provide an exhaustive analysis of the interplay between gut microbiota and CVD, but rather we identify important examples, where biological sex may be of relevance.

\section{GUT MICROBIOME}

The human gut hosts tens of thousands of microorganisms, up to 100 trillion microbes, which are collectively referred to as the gut microbiome $(11,12)$. The four dominant bacterial phyla 
in the human gut are Actinobacteria, Bacteroidetes, Firmicutes and Proteobacteria (13), and the Bacteroidetes and Firmicutes phyla constitute the vast majority of the dominant human gut microbiota (14). There is considerable microbial diversity among different individuals because of variations in age, genetics, geography, hygiene, nutrition and social behaviors $(15,16)$. The gut microbes have an important role in human health and disease, affecting body weight and digestion, the protection against infection, the risk of autoimmune diseases, as well as the body's response to drugs (17-21). In this context, perturbations
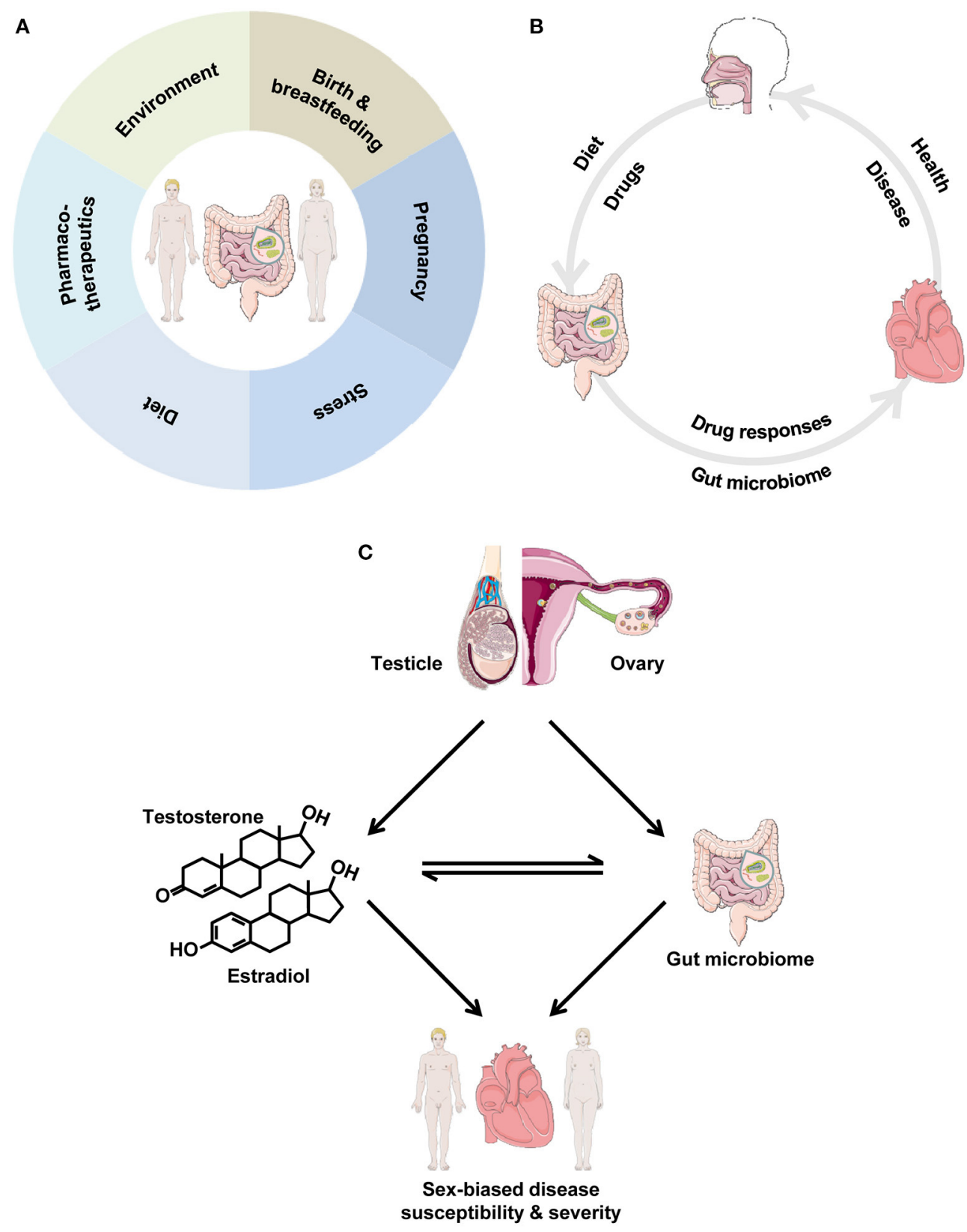

FIGURE 1 | (A) Factors impacting the gut microbiome in a sex-specific manner. The depicted factors can lead to marked differences between men and women in the intestinal microbial community. (B) The gut microbiome and the cardiovascular system. Dietary and other factors impact the gut microbiome, which, in turn, influences cardiovascular health. In disease, drugs elicit responses in the gut microbiome, which, in turn, influences the progression of cardiovascular disease. (C)

Interrelationships between biological sex, gut microbiota and the cardiovascular system. We propose the cardiovascular-gut microbiome-sex axis, where the cross-talk between gut microbiota and sex impacts cardiovascular health and disease. Gonadal sex gives rise to male-female hormones and impacts the gut microbiome. In turn, there is a close, bi-directional interaction between sex hormones and gut microbiota, as they influence each other, thereby leading to sex-biased disease susceptibility and severity, ultimately leading to the observed sex differences in cardiovascular disease. 
of the intestinal microbial community through dietary and environmental factors, as well as genetic factors, among others, can lead to the development of various diseases, including autism, autoimmune diseases, cancer, CVD, diabetes, obesity and other diseases $(10,18,22-30)$. Technological advances in the genomic and metabonomic fields, as well as in the assessment of the composition of the intestinal microbiome, have improved our knowledge and understanding of the complex interaction of the gut microbiome with the CV system. Recent findings highlight the potential benefit of developing microbiometargeted therapies for CVD prevention and treatment, thereby pointing to possible applications in personalized medicine $(31,32)$.

\section{OVERVIEW OF THE INTERPLAY BETWEEN THE GUT MICROBIOME AND THE CV SYSTEM}

Alterations in gut microbiota influence the CV system and can lead to the development of CVD (Figure 1B). The intestinal microbiota produce a large number of metabolites, some of which are absorbed into the systemic circulation and play a bioactive role, while others are further metabolized by host enzymes and thus become agents of microbial influence on the host CV system $(9,10,33)$. As a result, the intestinal tract with its microbes can act as an "endocrine-like" organ, impacting the distal CV target organs through a variety of metabolismrelated processes, thereby affecting the onset and progression of CVD. In this section, we highlight important examples with particular emphasis on how this interaction might impinge on the development of CVD.

\section{Hypertension}

Hypertension is a major risk factor for a variety of CVD (34). Gut dysbiosis-an imbalance of gut microbiota-has been linked to hypertension. Significant changes in the gut microbiome have been reported in human hypertensive patients and different hypertensive animal models, including spontaneously hypertensive rats, Dahl salt-sensitive rats, the chronic angiotensin II infusion rat model and high-salt diet-fed mice (35-38). In particular, a dysbiotic pattern was reported in spontaneously hypertensive rats and the chronic angiotensin II infusion rat model. This included decreased microbial richness and an increased Firmicutes:Bacteroidetes ratio, thereby leading to decreases in bacteria that produce the short-chain fatty acids (SCFA) acetate and butyrate (35). SCFA are major bioactive metabolites of gut microbiota, by which the host's biological processes and distal organs can be influenced. In this context, SCFA can regulate blood pressure by acting on various $G$ protein coupled receptors (39). Transplantation studies have indicated a causal relationship between gut dysbiosis and hypertension. Transplant of cecal contents from hypertensive rats into normotensive rats led to increased systolic blood pressure, as well as decreased microbial richness and an increased Firmicutes:Bacteroidetes ratio (40, 41). Furthermore, fecal transplantation from hypertensive human patients to germfree mice led to increased blood pressure in the mice (38). Mouse studies showed that a diet high in fiber increased the prevalence of Bacteroides acidifaciens compared with mice fed a control diet (42). This was associated with increased levels of one of the main metabolites of the gut microbiota, the SCFA acetate, which may confer protection against the development of hypertension (42). In contrast, high salt intake, which can lead to hypertension, depleted Lactobacillus murinus in mice, and treatment of mice with $\mathrm{L}$. murinus prevented salt-sensitive hypertension by modulating $\mathrm{T}$ helper 17 cells (36). Along this line, a moderate high-salt challenge in a pilot study in humans reduced intestinal survival of Lactobacillus spp., increased $\mathrm{T}$ helper 17 cells and increased blood pressure (36). Collectively, these data reveal the gut microbiota as a crucial regulator of blood pressure and indicate that dietary interventions may be useful in manipulating intestinal microbial composition and function to protect against hypertension.

\section{Atherosclerosis}

Atherosclerosis is a leading cause of various CVD, including coronary artery disease, stroke and peripheral artery disease. Earlier studies suggested that bacteria from the gut may correlate with disease markers of atherosclerosis (43). Since then, a number of studies has shown that the gut microbiome plays an important role in a variety of atherosclerotic conditions (44-48). A mechanistic link between gut microbiota and the development of atherosclerosis has been established. In particular, bacteria in the gut metabolize dietary phosphatidylcholine to trimethylamine, which crosses the gut-epithelial barrier and is then carried to the liver, where it is subsequently metabolized to the proatherogenic molecule trimethylamine-N-oxide (TMAO) (49-51). Importantly, plasma TMAO levels have been associated with mortality in patients with stable coronary artery disease, as well as in patients with peripheral artery disease, independent of traditional risk factors $(52,53)$. In an experimental model of myocardial infarction, decreased left ventricular function was underlain by increased gut permeability, mediated by tight junction protein suppression, and microbial translocation, thereby triggering systemic inflammation, ultimately contributing to the pathogenesis of CVD (54). Notably, probiotic administration conferred cardioprotective effects, including improved left ventricular function $(55,56)$. Collectively, these data demonstrate a key role of gut microbiota in the development of atherosclerosis and suggest that the use of probiotics, in addition to standard drug therapies, may provide additional benefits for patients with coronary artery disease, myocardial infarction and other atherosclerotic conditions.

\section{Heart Failure}

Heart failure (HF) is a devastating syndrome with poor prognosis. Gut microbiota and their metabolites produced from dietary metabolism have been linked to HF. To this extent, gut dysbiosis with decreased microbial richness and increased gut permeability has been reported in patients with $\operatorname{HF}(57,58)$, as well as in mice with pressure overload-induced HF (59). 
Further studies in humans have shown that the gut microbiomederived metabolite TMAO is increased in $\mathrm{HF}$ and that its levels are associated with poor prognosis (60-64). Studies with experimental animals have suggested a causal role of TMAO in the development of HF. In particular, treatment of rodents with TMAO led to myocardial hypertrophy and maladaptive remodeling, including ventricular dilation and wall thinning, systolic dysfunction and increased fibrosis $(65,66)$. Collectively, these data suggest a key role of gut microbiota and their metabolites in the pathogenesis and progression of HF.

\section{BRIEF OVERVIEW OF SEX DIFFERENCES IN CVD}

There are pronounced differences between men and women in the epidemiology, manifestation, pathophysiology, treatment and prognosis of CVD. As these have been reviewed recently elsewhere $(3,76,77)$, a brief overview is provided here. The incidence of CVD differs significantly between men and women; for example, women have a greater risk of developing Takotsubo cardiomyopathy than men (78). The association of major modifiable risk factors with incident myocardial infarction differs between the sexes and age influences this interaction significantly $(79,80)$. Consequently, the younger age of onset of acute myocardial infarction in men $(\sim 10$ years earlier than women) is largely explained by higher levels of risk factors, including abnormal lipids and smoking (79). In addition, women may have risk factors that are unique to them, such as preeclampsia (high blood pressure during pregnancy) and gestational diabetes, thereby increasing the risk of CVD in female individuals only. Women are also more likely to present with $\mathrm{HF}$ with preserved ejection fraction $(81,82)$, which may be due to sex-biased remodeling of myocardial extracellular matrix (83), and the decline of estrogen at menopause might contribute to its pathogenesis (84). Along this line, under pressure overload, there is a higher proportion of male patients with increased left ventricular mass and enddiastolic diameter, and decreased left ventricular relative wall thickness and function (85-91), associated with greater activation of inflammatory factors $(92,93)$. Physiological differences between men and women may also lead to sex differences in the response to treatment $(2,94-97)$. Overall, there are significant sex differences in the outcome of a variety of $\mathrm{CV}$ disorders (98-100).

\section{SEX DIFFERENCES IN THE COMPOSITION OF THE GUT MICROBIOME}

Human and animal studies have shown that biological sex has an impact on gut microbial composition (Table 1). In particular, significant differences in the composition of gut microbiota between healthy men and women have been reported, with women appearing to have lower Bacteroidetes abundance compared with men (67-70). The gut microbe-sex interaction, however, is, not surprisingly, affected by obesity, as the abundance of the Bacteroides genus was reported to be lower in
TABLE 1 | Sex differences in the gut microbiome.

\begin{tabular}{llc}
\hline Component & Sex difference & References \\
\hline Bacteroides & healthy men $>$ healthy women & $(67-70)$ \\
Prevotella & healthy men $>$ healthy women & $(69)$ \\
Bacteroides & obese men $<$ obese women & $(71)$ \\
Firmicutes & obese men $<$ obese women & $(71)$ \\
Bacteroides & $\begin{array}{l}\text { healthy male mice }>\text { healthy } \\
\text { female mice } \\
\text { healthy male mice }>\text { healthy }\end{array}$ \\
Ruminococcaceae & female mice \\
peptostreptococcaceae & $\begin{array}{l}\text { healthy male mice }<\text { healthy } \\
\text { female mice } \\
\text { healthy male mice }<\text { healthy }\end{array}$ \\
TMAO & female mice \\
male $>$ female rats fed an \\
oligofructose-supplemented diet
\end{tabular}

SCFA, short-chain fatty acids; TMAO, trimethylamine-N-oxide.

men than in women with a body mass index $>33$ (71). A study of different strains of mice showed that when considering the data at the single strain level, several taxa exhibited significant differences in abundance between the sexes (101). Among these, Bacteroidetes abundance is lower in female mice compared with male mice (72). Interestingly, sex differences in the gut microbiome appear to be responsible for hormone-dependent regulation of autoimmune disease (19). Along this line, in an experimental model of colitis, sex differences in gut microbiota composition were associated with sex-biased severity of the disease (73). Studies in rodents have shown that the levels of the gut microbiome-derived metabolite TMAO are higher in females than in males $(74,102)$. Biological sex also influences the interaction between the gut microbiome and environmental factors, such as diet $(75,101,103,104)$. For example, the interaction between dietary habits, such as yogurt consumption, and the gut microbiota is significantly different between healthy young male and female adults (105). Collectively, these data demonstrate that microbial composition and diversity differ significantly between the sexes. In this context, we put forward that differences in microbial composition and function between men and women may be a contributing factor to the observed sex differences in CVD (Figure 1C).

\section{REGULATION OF THE GUT MICROBIOME BY SEX HORMONES}

A large body of literature demonstrates that sex hormones modulate CV physiology and pathology. Of relevance, among the various factors underlying sex differences in CVD, such as sex chromosomes and (epi)genetic factors $(3,106)$, sex hormones appear to be crucial. For example, the steroid hormone $17 \beta$ estradiol (E2) and its receptors (ER) are thought to play a major role (107-111). The E2/ER axis has been shown to have vast effects in the CV system, regulating, for example, contractile function (micro), vascular function, metabolic processes, calcium 
signaling, gene expression and protein abundance (112-126), which can be sex-dependent (109, 127-132).

Along this line, among various types of hormones with regulatory effects, sex hormones have a key role in the regulation of the distribution of the gut microbiome. In this context, sex hormones affect gene expression and other processes of gut microbiota, thereby influencing intestinal microbial composition and function. In parallel, the microbial community also alters sex hormone levels, thereby regulating disease development and outcome $(19,72)$. Therefore, there is a complex interaction between gut microbiota and sex hormones. Interestingly, this is true not only for mammals but also for fish. Treatment of zebrafish with E2 altered the intestinal microbial composition significantly, which may lead to further physiological changes in the host (133). Androgens also appear to influence the composition of the gut microbiome. In fact, in pathological situations of hormonal excess, such as polycystic ovary syndrome, there is decreased microbial diversity and changes in microbial composition that are associated with metabolic dysregulation, thereby indicating that hyperandrogenism may be linked with gut dysbiosis in women with this disorder (134-137). Moreover, testosterone treatment after gonadectomy prevented the significant changes in gut microbiota composition that occurred in untreated males (101). Further studies in humans have shown that the composition of gut microbiota differs significantly among women with different hormonal status (67). The key role of sex hormones in microbial composition is further supported by studies in mice with gonadectomy, which resulted in an altered gut microbiome (101). To this extent, it was shown that the deficiency of androgens alters the intestinal microbiome and induces abdominal obesity in a diet-dependent manner (138). Collectively, these data indicate that sex hormones mediate (at least partly) the differences in gut microbiota composition between the sexes. Currently, it is unclear how sex hormones regulate the composition and function of the gut microbial community. Further research is warranted.

\section{CHALLENGES AND OPPORTUNITIES}

Potential differences in microbial composition, diversity and function between humans and animal models might limit the translation of experimental studies with animals. Furthermore, given the major impact that environmental factors have on gut microbiota, it needs to be highlighted that most environmental conditions of humans differ significantly from those of laboratory animals. In addition, estrous cycle-related changes in gut microbiota in rodents might not reflect any changes due to menstruation in women. Nevertheless, the degree of any inconsistencies remains to be determined. Lastly, abundant species do not necessarily confer abundant molecular functions, underscoring the importance of a functional analysis to understand microbial communities (139).

The role of sex has yet underestimated consequences for physiology and pathology (140). A better understanding of the mechanisms accounting for sex differences in microbial composition could provide opportunities for the development of novel sex-specific diagnostic tests and therapeutic approaches for
CVD. Given the evidence provided by the current literature, we put forward that the "gut microbiome status" in the context of the patient's sex should be taken into account in CVD management and we provide the following specific recommendations as a paradigm: (1) a dietary intervention to modulate gut microbiota could be an innovative nutritional therapeutic strategy for hypertension; (2) a new therapeutic intervention by probiotics targeting gut bacteria and protecting gut function may be a potential option to improve $\mathrm{CV}$ outcomes post-myocardial infarction; (3) strategies for the modulation of TMAO levels could be beneficial in the prevention of HF; (4) approaches to reduce the levels of TMAO in patients with HF could improve long-term prognosis. In this context, an experimental approach for the directed remodeling of the mouse gut microbiome with peptide treatment was recently shown to inhibit the development of atherosclerosis (141).

Moreover, the gut has been shown to be a target of severe acute respiratory syndrome coronavirus 2 (SARS-CoV2). In fact, gastrointestinal manifestations of SARS-CoV-2, such as anorexia, nausea, vomiting, diarrhea and hepato-cellular injury (transaminitis), among others, have been widely reported $(142,143)$. SARS-CoV-2 is primarily considered a respiratory pathogen. Nevertheless, patients with coronavirus disease 2019 (COVID-19) present with gastrointestinal symptoms, given that angiotensin-converting enzyme 2 (ACE2), which SARS-CoV2 uses as a host cell entry receptor (144), is ubiquitously present in the human gut, including small intestine and colonic enterocytes, hepatocytes and cholangiocytes. However, the effects and impact of SARS-CoV-2 on host microbial flora and gut microbiota composition are unclear. Interestingly, COVID-19 patients appear to have sex-dependent CV risk and complications. However, the underlying mechanisms are incompletely understood $(145,146)$. To this extent, we put forward the notion that SARS-CoV-2 may lead to significant sex differences in the gut microbiome status of COVID-19 patients, which, in turn, impacts the CV system, thereby contributing to the observed sex-biased CV complications in these patients. This further highlights the opportunity of employing the gut microbiome as a novel target for sex-specific therapeutic interventions for (severe) CV complications in patients with COVID-19. Further research is warranted.

\section{CONCLUSIONS}

The mechanisms by which the gut microbiome affects CV (patho) physiology are incompletely understood. From several human and animal studies, it is clear that the gut microbiome exerts sex-biased effects in health and disease. At least in part, sex hormones account for these sex-dependent effects in a complex bi-directional interaction with the microbial community. Gut microbiota may become a novel target for pharmacological or dietary interventions as part of new preventive and therapeutic strategies in CVD. A better understanding of the effects of biological sex and considering its role in such novel approaches will improve clinical care and management via new strategies for the prevention, diagnosis and treatment of disease in both men and women. 


\section{AUTHOR CONTRIBUTIONS}

GK conceived the work. SL and GK wrote the manuscript. Both authors contributed to the article and approved the submitted version.

\section{REFERENCES}

1. Collaborators. GCoD. Global, regional, and national age-sex-specific mortality for 282 causes of death in 195 countries and territories, 1980-2017: a systematic analysis for the global burden of disease study 2017. Lancet. (2018) 392:1736-88. doi: 10.1016/S0140-6736(18)32203-7

2. Gaignebet L, Kararigas G. En route to precision medicine through the integration of biological sex into pharmacogenomics. Clin Sci. (2017) 131:329-42. doi: $10.1042 / C S 20160379$

3. Regitz-Zagrosek V, Kararigas G. Mechanistic pathways of sex differences in cardiovascular disease. Physiol Rev. (2017) 97:1-37. doi: 10.1152/physrev.00021.2015

4. Yusuf S, Joseph P, Rangarajan S, Islam S, Mente A, Hystad P, et al. Modifiable risk factors, cardiovascular disease, and mortality in 155 722 individuals from 21 high-income, middle-income, and low-income countries (PURE): a prospective cohort study. Lancet. (2020) 395:795-808. doi: 10.1016/S0140-6736(19)32008-2

5. Mirzaei H, Di Biase S, Longo VD. Dietary interventions, cardiovascular aging, and disease: animal models and human studies. Circ Res. (2016) 118:1612-25. doi: 10.1161/CIRCRESAHA.116.307473

6. Ley SH, Hamdy O, Mohan V, Hu FB. Prevention and management of type 2 diabetes: dietary components and nutritional strategies. Lancet. (2014) 383:1999-2007. doi: 10.1016/S0140-6736(14)60613-9

7. Mozaffarian D. Dietary and policy priorities for cardiovascular disease, diabetes, and obesity: a comprehensive review. Circulation. (2016) 133:187225. doi: 10.1161/CIRCULATIONAHA.115.018585

8. Bechthold A, Boeing H, Schwedhelm C, Hoffmann G, Knuppel S, Iqbal K, et al. Food groups and risk of coronary heart disease, stroke and heart failure: a systematic review and dose-response meta-analysis of prospective studies. Crit Rev Food Sci Nutr. (2019) 59:1071-90. doi: 10.1080/10408398.2017.1392288

9. Tang WH, Kitai $\mathrm{T}$, Hazen SL. Gut microbiota in cardiovascular health and disease. Circ Res. (2017) 120:1183-96. doi: 10.1161/CIRCRESAHA.117.309715

10. Tang WH, Hazen SL. The gut microbiome and its role in cardiovascular diseases. Circulation. (2017) 135:1008-10. doi: 10.1161/CIRCULATIONAHA.116.024251

11. Ley RE, Peterson DA, Gordon JI. Ecological and evolutionary forces shaping microbial diversity in the human intestine. Cell. (2006) 124:837-48. doi: 10.1016/j.cell.2006.02.017

12. Eckburg PB, Bik EM, Bernstein CN, Purdom E, Dethlefsen L, Sargent M, et al. Diversity of the human intestinal microbial flora. Science. (2005) 308:1635-8. doi: 10.1126/science.1110591

13. Khanna S, Tosh PK. A clinician's primer on the role of the microbiome in human health and disease. Mayo Clin Proc. (2014) 89:107-14. doi: 10.1016/j.mayocp.2013.10.011

14. Zoetendal EG, Rajilic-Stojanovic M, de Vos WM. High-throughput diversity and functionality analysis of the gastrointestinal tract microbiota. Gut. (2008) 57:1605-15. doi: 10.1136/gut.2007.133603

15. Yatsunenko T, Rey FE, Manary MJ, Trehan I, Dominguez-Bello MG, Contreras $\mathrm{M}$, et al. Human gut microbiome viewed across age and geography. Nature. (2012) 486:222-7. doi: 10.1038/nature11053

16. Flint HJ. The impact of nutrition on the human microbiome. Nutr Rev. (2012) 70(Suppl. 1):S10-3. doi: 10.1111/j.1753-4887.2012.00499.x

17. van Nood E, Vrieze A, Nieuwdorp M, Fuentes S, Zoetendal EG, de Vos WM, et al. Duodenal infusion of donor feces for recurrent clostridium difficile. $N$ Engl J Med. (2013) 368:407-15. doi: 10.1056/NEJMoa1205037

18. Vatanen $\mathrm{T}$, Kostic AD, d'Hennezel E, Siljander H, Franzosa EA, Yassour $\mathrm{M}$, et al. Variation in microbiome LPS immunogenicity

\section{FUNDING}

GK acknowledges lab support provided by grants from the Icelandic Research Fund (217946-051), Icelandic Cancer Society Research Fund and University of Iceland Research Fund.

contributes to autoimmunity in humans. Cell. (2016) 165:842-53. doi: 10.1016/j.cell.2016.04.007

19. Markle JG, Frank DN, Mortin-Toth S, Robertson CE, Feazel LM, Rolle-Kampczyk U, et al. Sex differences in the gut microbiome drive hormone-dependent regulation of autoimmunity. Science. (2013) 339:10848. doi: 10.1126/science.1233521

20. Gopalakrishnan V, Spencer CN, Nezi L, Reuben A, Andrews MC, Karpinets TV, et al. Gut microbiome modulates response to anti-PD1 immunotherapy in melanoma patients. Science. (2018) 359:97-103. doi: $10.1126 /$ science.aan 4236

21. Uribe-Herranz M, Rafail S, Beghi S, Gil-de-Gomez L, Verginadis I, Bittinger $\mathrm{K}$, et al. Gut microbiota modulate dendritic cell antigen presentation and radiotherapy-induced antitumor immune response. J Clin Invest. (2020) 130:466-79. doi: 10.1172/JCI124332

22. Gopalakrishnan V, Helmink BA, Spencer CN, Reuben A, Wargo JA. The influence of the gut microbiome on cancer, immunity, and cancer immunotherapy. Cancer Cell. (2018) 33:570-80. doi: $10.1016 /$ j.ccell.2018.03.015

23. Turnbaugh PJ, Ley RE, Mahowald MA, Magrini V, Mardis ER, Gordon JI. An obesity-associated gut microbiome with increased capacity for energy harvest. Nature. (2006) 444:1027-31. doi: 10.1038/nature05414

24. Forslund K, Hildebrand F, Nielsen T, Falony G, Le Chatelier E, Sunagawa $\mathrm{S}$, et al. Disentangling type 2 diabetes and metformin treatment signatures in the human gut microbiota. Nature. (2015) 528:262-6. doi: 10.1038/nature15766

25. Vuong HE, Hsiao EY. Emerging roles for the gut microbiome in autism spectrum disorder. Biol Psychiatry. (2017) 81:411-23. doi: 10.1016/j.biopsych.2016.08.024

26. Hall $\mathrm{AB}$, Tolonen $\mathrm{AC}$, Xavier RJ. Human genetic variation and the gut microbiome in disease. Nat Rev Genet. (2017) 18:690-9. doi: 10.1038/nrg.2017.63

27. McKenzie C, Tan J, Macia L, Mackay CR. The nutrition-gut microbiomephysiology axis and allergic diseases. Immunol Rev. (2017) 278:277-95. doi: 10.1111/imr.12556

28. Ghaisas S, Maher J, Kanthasamy A. Gut microbiome in health and disease: linking the microbiome-gut-brain axis and environmental factors in the pathogenesis of systemic and neurodegenerative diseases. Pharmacol Ther. (2016) 158:52-62. doi: 10.1016/j.pharmthera.2015.11.012

29. Rogers GB, Keating DJ, Young RL, Wong ML, Licinio J, Wesselingh S. From gut dysbiosis to altered brain function and mental illness: mechanisms and pathways. Mol Psychiatry. (2016) 21:738-48. doi: 10.1038/mp.2016.50

30. Abdollahi-Roodsaz S, Abramson SB, Scher JU. The metabolic role of the gut microbiota in health and rheumatic disease: mechanisms and interventions. Nat Rev Rheumatol. (2016) 12:446-55. doi: 10.1038/nrrheum.2016.68

31. Kurilshikov A, van den Munckhof ICL, Chen L, Bonder MJ, Schraa $\mathrm{K}$, Rutten JHW, et al. Gut microbial associations to plasma metabolites linked to cardiovascular phenotypes and risk. Circ Res. (2019) 124:1808-20. doi: 10.1161/CIRCRESAHA.118.314642

32. Zhernakova DV, Le TH, Kurilshikov A, Atanasovska B, Bonder MJ, Sanna $\mathrm{S}$, et al. Individual variations in cardiovascular-disease-related protein levels are driven by genetics and gut microbiome. Nat Genet. (2018) 50:1524-32. doi: 10.1038/s41588-018-0224-7

33. Jonsson AL, Backhed F. Role of gut microbiota in atherosclerosis. Nat Rev Cardiol. (2017) 14:79-87. doi: 10.1038/nrcardio.2016.183

34. Sabbatini AR, Kararigas G. Estrogen-related mechanisms in sex differences of hypertension and target organ damage. Biol Sex Differ. (2020) 11:31. doi: 10.1186/s13293-020-00306-7

35. Yang T, Santisteban MM, Rodriguez V, Li E, Ahmari N, Carvajal $\mathrm{JM}$, et al. Gut dysbiosis is linked to hypertension. Hypertension. 


\section{(2015) 65:1331-40. doi: 10.1161/HYPERTENSIONAHA.115.}

05315

36. Wilck N, Matus MG, Kearney SM, Olesen SW, Forslund K, Bartolomaeus $\mathrm{H}$, et al. Salt-responsive gut commensal modulates TH17 axis and disease. Nature. (2017) 551:585-9. doi: 10.1038/nature24628

37. Mell B, Jala VR, Mathew AV, Byun J, Waghulde H, Zhang Y, et al. Evidence for a link between gut microbiota and hypertension in the Dahl rat. Physiol Genomics. (2015) 47:187-97. doi: 10.1152/physiolgenomics.00136.2014

38. Li J, Zhao F, Wang Y, Chen J, Tao J, Tian G, et al. Gut microbiota dysbiosis contributes to the development of hypertension. Microbiome. (2017) 5:14. doi: 10.1186/s40168-016-0222-x

39. Pluznick JL, Protzko RJ, Gevorgyan H, Peterlin Z, Sipos A, Han J, et al. Olfactory receptor responding to gut microbiota-derived signals plays a role in renin secretion and blood pressure regulation. Proc Natl Acad Sci USA. (2013) 110:4410-5. doi: 10.1073/pnas.1215927110

40. Durgan DJ, Ganesh BP, Cope JL, Ajami NJ, Phillips SC, Petrosino $\mathrm{JF}$, et al. Role of the gut microbiome in obstructive sleep apnea-induced hypertension. Hypertension. (2016) 67:469-74. doi: 10.1161/HYPERTENSIONAHA.115.06672

41. Adnan S, Nelson JW, Ajami NJ, Venna VR, Petrosino JF, Bryan RM, et al. Alterations in the gut microbiota can elicit hypertension in rats. Physiol Genomics. (2017) 49:96-104. doi: 10.1152/physiolgenomics.00081.2016

42. Marques FZ, Nelson E, Chu PY, Horlock D, Fiedler A, Ziemann $M$, et al. High-fiber diet and acetate supplementation change the gut microbiota and prevent the development of hypertension and heart failure in hypertensive mice. Circulation. (2017) 135:964-77. doi: 10.1161/CIRCULATIONAHA.116.024545

43. Koren O, Spor A, Felin J, Fak F, Stombaugh J, Tremaroli V, et al. Human oral, gut, and plaque microbiota in patients with atherosclerosis. Proc Natl Acad Sci USA. (2011) 108(Suppl. 1):4592-8. doi: 10.1073/pnas.1011383107

44. Jie Z, Xia H, Zhong SL, Feng Q, Li S, Liang S, et al. The gut microbiome in atherosclerotic cardiovascular disease. Nat Commun. (2017) 8:845. doi: 10.1038/s41467-017-00900-1

45. Emoto T, Yamashita T, Sasaki N, Hirota Y, Hayashi T, So A, et al. Analysis of gut microbiota in coronary artery disease patients: a possible link between gut microbiota and coronary artery disease. J Atheroscler Thromb. (2016) 23:908-21. doi: $10.5551 /$ jat.32672

46. Emoto T, Yamashita T, Kobayashi T, Sasaki N, Hirota Y, Hayashi T, et al. Characterization of gut microbiota profiles in coronary artery disease patients using data mining analysis of terminal restriction fragment length polymorphism: gut microbiota could be a diagnostic marker of coronary artery disease. Heart Vessels. (2017) 32:39-46. doi: 10.1007/s00380-016-0841-y

47. Yoshida N, Emoto T, Yamashita T, Watanabe H, Hayashi T, Tabata T, et al. Bacteroides vulgatus and bacteroides dorei reduce gut microbial lipopolysaccharide production and inhibit atherosclerosis. Circulation. (2018) 138:2486-98. doi: 10.1161/CIRCULATIONAHA.118.033714

48. Liu $\mathrm{H}$, Chen $\mathrm{X}, \mathrm{Hu} \mathrm{X}$, Niu $\mathrm{H}$, Tian R, Wang $\mathrm{H}$, et al. Alterations in the gut microbiome and metabolism with coronary artery disease severity. Microbiome. (2019) 7:68. doi: 10.1186/s40168-019-0683-9

49. Koeth RA, Levison BS, Culley MK, Buffa JA, Wang Z, Gregory JC, et al. gamma-Butyrobetaine is a proatherogenic intermediate in gut microbial metabolism of L-carnitine to TMAO. Cell Metab. (2014) 20:799-812. doi: 10.1016/j.cmet.2014.10.006

50. Wang Z, Klipfell E, Bennett BJ, Koeth R, Levison BS, Dugar B, et al. Gut flora metabolism of phosphatidylcholine promotes cardiovascular disease. Nature. (2011) 472:57-63. doi: 10.1038/nature09922

51. Tang WH, Wang Z, Levison BS, Koeth RA, Britt EB, Fu X, et al. Intestinal microbial metabolism of phosphatidylcholine and cardiovascular risk. NEngl J Med. (2013) 368:1575-84. doi: 10.1056/NEJMoa1109400

52. Senthong V, Wang Z, Li XS, Fan Y, Wu Y, Tang WH, et al. Intestinal microbiota-generated metabolite trimethylamine-N-Oxide and 5year mortality risk in stable coronary artery disease: the contributory role of intestinal microbiota in a COURAGE-like patient cohort. J Am Heart Assoc. (2016) 5:e002816. doi: 10.1161/JAHA.115.002816

53. Senthong V, Wang Z, Fan Y, Wu Y, Hazen SL, Tang WH. Trimethylamine $\mathrm{n}$-oxide and mortality risk in patients with peripheral artery disease. J Am Heart Assoc. (2016) 5:e004237. doi: 10.1161/JAHA.116.004237
54. Zhou X, Li J, Guo J, Geng B, Ji W, Zhao Q, et al. Gut-dependent microbial translocation induces inflammation and cardiovascular events after ST-elevation myocardial infarction. Microbiome. (2018) 6:66. doi: 10.1186/s40168-018-0441-4

55. Gan XT, Ettinger G, Huang CX, Burton JP, Haist JV, Rajapurohitam V, et al. Probiotic administration attenuates myocardial hypertrophy and heart failure after myocardial infarction in the rat. Circ Heart Fail. (2014) 7:491-9. doi: 10.1161/CIRCHEARTFAILURE.113.000978

56. Tang TWH, Chen HC, Chen CY, Yen CYT, Lin CJ, Prajnamitra RP, et al. Loss of gut microbiota alters immune system composition and cripples postinfarction cardiac repair. Circulation. (2019) 139:647-59. doi: 10.1161/CIRCULATIONAHA.118.035235

57. Luedde M, Winkler T, Heinsen FA, Ruhlemann MC, Spehlmann ME, Bajrovic A, et al. Heart failure is associated with depletion of core intestinal microbiota. ESC Heart Fail. (2017) 4:282-90. doi: 10.1002/ehf2.12155

58. Pasini E, Aquilani R, Testa C, Baiardi P, Angioletti S, Boschi F, et al. Pathogenic gut flora in patients with chronic heart failure. JACC Heart Fail. (2016) 4:220-7. doi: 10.1016/j.jchf.2015.10.009

59. Boccella N, Paolillo R, Coretti L, D’Apice S, Lama A, Giugliano G, et al. Transverse aortic constriction induces gut barrier alterations, microbiota remodeling and systemic inflammation. Sci Rep. (2021) 11:7404. doi: 10.1038/s41598-021-86651-y

60. Hayashi T, Yamashita T, Watanabe H, Kami K, Yoshida N, Tabata T, et al. Gut microbiome and plasma microbiome-related metabolites in patients with decompensated and compensated heart failure. Circ J. (2018) 83:182-92. doi: 10.1253/circj.CJ-18-0468

61. Cui X, Ye L, Li J, Jin L, Wang W, Li S, et al. Metagenomic and metabolomic analyses unveil dysbiosis of gut microbiota in chronic heart failure patients. Sci Rep. (2018) 8:635. doi: 10.1038/s41598-017-18756-2

62. Tang WH, Wang Z, Fan Y, Levison B, Hazen JE, Donahue LM, et al. Prognostic value of elevated levels of intestinal microbe-generated metabolite trimethylamine-N-oxide in patients with heart failure: refining the gut hypothesis. J Am Coll Cardiol. (2014) 64:1908-14. doi: 10.1016/j.jacc.2014.02.617

63. Suzuki T, Heaney LM, Bhandari SS, Jones DJ, Ng LL. Trimethylamine $\mathrm{N}$-oxide and prognosis in acute heart failure. Heart. (2016) 102:841-8. doi: 10.1136/heartjnl-2015-308826

64. Schiattarella GG, Sannino A, Toscano E, Giugliano G, Gargiulo G, Franzone A, et al. Gut microbe-generated metabolite trimethylamine- $\mathrm{N}$-oxide as cardiovascular risk biomarker: a systematic review and dose-response meta-analysis. Eur Heart J. (2017) 38:2948-56. doi: 10.1093/eurheartj/e $\mathrm{h} \times 342$

65. Li Z, Wu Z, Yan J, Liu H, Liu Q, Deng Y, et al. Gut microbe-derived metabolite trimethylamine $\mathrm{N}$-oxide induces cardiac hypertrophy and fibrosis. Lab Invest. (2019) 99:346-57. doi: 10.1038/s41374-018-0091-y

66. Organ CL, Otsuka H, Bhushan S, Wang Z, Bradley J, Trivedi R, et al. Choline diet and its gut microbe-derived metabolite, trimethylamine n-oxide, exacerbate pressure overload-induced heart failure. Circ Heart Fail. (2016) 9:e002314. doi: 10.1161/CIRCHEARTFAILURE.115.0 02314

67. Santos-Marcos JA, Rangel-Zuniga OA, Jimenez-Lucena R, QuintanaNavarro GM, Garcia-Carpintero S, Malagon MM, et al. Influence of gender and menopausal status on gut microbiota. Maturitas. (2018) 116:43-53. doi: 10.1016/j.maturitas.2018.07.008

68. Dominianni C, Sinha R, Goedert JJ, Pei Z, Yang L, Hayes RB, et al. Sex, body mass index, and dietary fiber intake influence the human gut microbiome. PLoS ONE. (2015) 10:e0124599. doi: 10.1371/journal.pone.0124599

69. Mueller S, Saunier K, Hanisch C, Norin E, Alm L, Midtvedt T, et al. Differences in fecal microbiota in different European study populations in relation to age, gender, and country: a cross-sectional study. Appl Environ Microbiol. (2006) 72:1027-33. doi: 10.1128/AEM.72.2.1027-1033.2006

70. Ding T, Schloss PD. Dynamics and associations of microbial community types across the human body. Nature. (2014) 509:357-60. doi: 10.1038/nature13178

71. Haro C, Rangel-Zuniga OA, Alcala-Diaz JF, Gomez-Delgado F, PerezMartinez P, Delgado-Lista J, et al. Intestinal microbiota is influenced by gender and body mass index. PLoS ONE. (2016) 11:e0154090. doi: 10.1371/journal.pone. 0154090 
72. Yurkovetskiy L, Burrows M, Khan AA, Graham L, Volchkov P, Becker L, et al. Gender bias in autoimmunity is influenced by microbiota. Immunity. (2013) 39:400-12. doi: 10.1016/j.immuni.2013.08.013

73. Kozik AJ, Nakatsu CH, Chun H, Jones-Hall YL. Age, sex, and TNF associated differences in the gut microbiota of mice and their impact on acute TNBS colitis. Exp Mol Pathol. (2017) 103:311-9. doi: 10.1016/j.yexmp.2017.11.014

74. Gavaghan McKee CL, Wilson ID, Nicholson JK. Metabolic phenotyping of nude and normal (Alpk:ApfCD, C57BL10J) mice. J Proteome Res. (2006) 5:378-84. doi: 10.1021/pr050255h

75. Shastri P, McCarville J, Kalmokoff M, Brooks SP, Green-Johnson JM. Sex differences in gut fermentation and immune parameters in rats fed an oligofructose-supplemented diet. Biol Sex Differ. (2015) 6:13. doi: 10.1186/s13293-015-0031-0

76. Ventura-Clapier R, Dworatzek E, Seeland U, Kararigas G, Arnal JF, Brunelleschi S, et al. Sex in basic research: concepts in the cardiovascular field. Cardiovasc Res. (2017) 113:711-24. doi: 10.1093/cvr/cvx066

77. Colafella KMM, Denton KM. Sex-specific differences in hypertension and associated cardiovascular disease. Nat Rev Nephrol. (2018) 14:185-201. doi: 10.1038/nrneph.2017.189

78. Templin C, Ghadri JR, Diekmann J, Napp LC, Bataiosu DR, Jaguszewski M, et al. Clinical features and outcomes of takotsubo (Stress) cardiomyopathy. N Engl J Med. (2015) 373:929-38. doi: 10.1056/NEJMoa1406761

79. Anand SS, Islam S, Rosengren A, Franzosi MG, Steyn K, Yusufali $\mathrm{AH}$, et al. Risk factors for myocardial infarction in women and men: insights from the INTERHEART study. Eur Heart J. (2008) 29:932-40. doi: 10.1093/eurheartj/ehn018

80. Culic V, Eterovic D, Miric D. Meta-analysis of possible external triggers of acute myocardial infarction. Int J Cardiol. (2005) 99:1-8. doi: 10.1016/j.ijcard.2004.01.008

81. Lam CS, Carson PE, Anand IS, Rector TS, Kuskowski M, Komajda M, et al. Sex differences in clinical characteristics and outcomes in elderly patients with heart failure and preserved ejection fraction: the irbesartan in heart failure with preserved ejection fraction (I-PRESERVE) trial. Circ Heart Fail. (2012) 5:571-8. doi: 10.1161/CIRCHEARTFAILURE.112.970061

82. Beale AL, Meyer P, Marwick TH, Lam CSP, Kaye DM. Sex differences in cardiovascular pathophysiology: why women are overrepresented in heart failure with preserved ejection fraction. Circulation. (2018) 138:198-205. doi: 10.1161/CIRCULATIONAHA.118.034271

83. Dworatzek E, Baczko I, Kararigas G. Effects of aging on cardiac extracellular matrix in men and women. Proteomics Clin Appl. (2016) 10:84-91. doi: $10.1002 /$ prca.201500031

84. Sabbatini AR, Kararigas G. Menopause-related estrogen decrease and the pathogenesis of HFpEF: JACC review topic of the week. J Am Coll Cardiol. (2020) 75:1074-82. doi: 10.1016/j.jacc.2019.12.049

85. Aurigemma GP, Silver KH, McLaughlin M, Mauser J, Gaasch WH. Impact of chamber geometry and gender on left ventricular systolic function in patients $>60$ years of age with aortic stenosis. Am J Cardiol. (1994) 74:794-8. doi: 10.1016/0002-9149(94)90437-5

86. Carroll JD, Carroll EP, Feldman T, Ward DM, Lang RM, McGaughey D, et al. Sex-associated differences in left ventricular function in aortic stenosis of the elderly. Circulation. (1992) 86:1099-107. doi: 10.1161/01.CIR.86.4.1099

87. Douglas PS, Otto CM, Mickel MC, Labovitz A, Reid CL, Davis KB. Gender differences in left ventricle geometry and function in patients undergoing balloon dilatation of the aortic valve for isolated aortic stenosis. NHLBI Balloon Valvuloplasty Registry. Br Heart J. (1995) 73:548-54. doi: 10.1136/hrt.73.6.548

88. Villar AV, Llano M, Cobo M, Exposito V, Merino R, Martin-Duran R, et al. Gender differences of echocardiographic and gene expression patterns in human pressure overload left ventricular hypertrophy. J Mol Cell Cardiol. (2009) 46:526-35. doi: 10.1016/j.yjmcc.2008.12.024

89. Villari B, Campbell SE, Schneider J, Vassalli G, Chiariello M, Hess OM. Sex-dependent differences in left ventricular function and structure in chronic pressure overload. Eur Heart J. (1995) 16:1410-9. doi: 10.1093/oxfordjournals.eurheartj.a060749

90. Cleland JG, Swedberg K, Follath F, Komajda M, Cohen-Solal A, Aguilar JC, et al. The EuroHeart Failure survey programme- a survey on the quality of care among patients with heart failure in Europe. Part 1: patient characteristics and diagnosis. Eur Heart J. (2003) 24:442-63. doi: 10.1016/S0195-668X(02)00823-0

91. Garcia R, Salido-Medina AB, Gil A, Merino D, Gomez J, Villar AV, et al. Sexspecific regulation of miR-29b in the myocardium under pressure overload is associated with differential molecular, structural and functional remodeling patterns in mice and patients with aortic stenosis. Cells. (2020) 9:833. doi: $10.3390 /$ cells 9040833

92. Kararigas G, Dworatzek E, Petrov G, Summer H, Schulze TM, Baczko I, et al. Sex-dependent regulation of fibrosis and inflammation in human left ventricular remodelling under pressure overload. Eur J Heart Fail. (2014) 16:1160-7. doi: 10.1002/ejhf.171

93. Gaignebet L, Kandula MM, Lehmann D, Knosalla C, Kreil DP, Kararigas G. Sex-specific human cardiomyocyte gene regulation in left ventricular pressure overload. Mayo Clin Proc. (2020) 95:688-97. doi: 10.1016/j.mayocp.2019.11.026

94. Franconi F, Campesi I. Pharmacogenomics, pharmacokinetics and pharmacodynamics: interaction with biological differences between men and women. Br J Pharmacol. (2014) 171:580-94. doi: 10.1111/bph.12362

95. Jochmann N, Stangl K, Garbe E, Baumann G, Stangl V. Female-specific aspects in the pharmacotherapy of chronic cardiovascular diseases. Eur Heart J. (2005) 26:1585-95. doi: 10.1093/eurheartj/ehi397

96. Rathore SS, Wang Y, Krumholz HM. Sex-based differences in the effect of digoxin for the treatment of heart failure. N Engl J Med. (2002) 347:1403-11. doi: 10.1056/NEJMoa021266

97. Cui C, Huang C, Liu K, Xu G, Yang J, Zhou Y, et al. Large-scale in silico identification of drugs exerting sex-specific effects in the heart. J Transl Med. (2018) 16:236. doi: 10.1186/s12967-018-1612-6

98. Cramariuc D, Rogge BP, Lonnebakken MT, Boman K, Bahlmann E, Gohlke-Barwolf C, et al. Sex differences in cardiovascular outcome during progression of aortic valve stenosis. Heart. (2015) 101:209-14. doi: 10.1136/heartjnl-2014-306078

99. Martinez-Selles M, Doughty RN, Poppe K, Whalley GA, Earle N, Tribouilloy $\mathrm{C}$, et al. Gender and survival in patients with heart failure: interactions with diabetes and aetiology. Results from the MAGGIC individual patient meta-analysis. Eur J Heart Fail. (2012) 14:473-9. doi: 10.1093/eurjhf/hfs026

100. Petrov G, Dworatzek E, Schulze TM, Dandel M, Kararigas G, Mahmoodzadeh S, et al. Maladaptive remodeling is associated with impaired survival in women but not in men after aortic valve replacement. JACC Cardiovasc Imag. (2014) 7:1073-80. doi: 10.1016/j.jcmg.2014.06.017

101. Org E, Mehrabian M, Parks BW, Shipkova P, Liu X, Drake TA, et al. Sex differences and hormonal effects on gut microbiota composition in mice. Gut Microbes. (2016) 7:313-22. doi: 10.1080/19490976.2016.1203502

102. Stanley EG, Bailey NJ, Bollard ME, Haselden JN, Waterfield CJ, Holmes E, et al. Sexual dimorphism in urinary metabolite profiles of Han Wistar rats revealed by nuclear-magnetic-resonance-based metabonomics. Anal Biochem. (2005) 343:195-202. doi: 10.1016/j.ab.2005.01.024

103. Bolnick DI, Snowberg LK, Hirsch PE, Lauber CL, Org E, Parks B, et al. Individual diet has sex-dependent effects on vertebrate gut microbiota. Nat Commun. (2014) 5:4500. doi: 10.1038/ncomms5500

104. Bridgewater LC, Zhang C, Wu Y, Hu W, Zhang Q, Wang J, et al. Genderbased differences in host behavior and gut microbiota composition in response to high fat diet and stress in a mouse model. Sci Rep. (2017) 7:10776. doi: 10.1038/s41598-017-11069-4

105. Suzuki Y, Ikeda K, Sakuma K, Kawai S, Sawaki K, Asahara T, et al. Association between yogurt consumption and intestinal microbiota in healthy young adults differs by host gender. Front Microbiol. (2017) 8:847. doi: 10.3389/fmicb.2017.00847

106. Pei J, Harakalova M, Treibel TA, Lumbers RT, Boukens BJ, Efimov IR, et al. H3K27ac acetylome signatures reveal the epigenomic reorganization in remodeled non-failing human hearts. Clin Epigenetics. (2020) 12:106. doi: 10.1186/s13148-020-00895-5

107. Iorga A, Cunningham CM, Moazeni S, Ruffenach G, Umar S, Eghbali M. The protective role of estrogen and estrogen receptors in cardiovascular disease and the controversial use of estrogen therapy. Biol Sex Differ. (2017) 8:33. doi: 10.1186/s13293-017-0152-8

108. Murphy E. Estrogen signaling and cardiovascular disease. Circ Res. (2011) 109:687-96. doi: 10.1161/CIRCRESAHA.110.236687 
109. Murphy E, Steenbergen C. Estrogen regulation of protein expression and signaling pathways in the heart. Biol Sex Differ. (2014) 5:6. doi: 10.1186/2042-6410-5-6

110. Menazza S, Murphy E. The expanding complexity of estrogen receptor signaling in the cardiovascular system. Circ Res. (2016) 118:994-1007. doi: 10.1161/CIRCRESAHA.115.305376

111. Puglisi R, Mattia G, Care A, Marano G, Malorni W, Matarrese P. Nongenomic effects of estrogen on cell homeostasis and remodeling with special focus on cardiac ischemia/reperfusion injury. Front Endocrinol. (2019) 10:733. doi: 10.3389/fendo.2019.00733

112. Schubert C, Raparelli V, Westphal C, Dworatzek E, Petrov G, Kararigas G, et al. Reduction of apoptosis and preservation of mitochondrial integrity under ischemia/reperfusion injury is mediated by estrogen receptor beta. Biol Sex Differ. (2016) 7:53. doi: 10.1186/s13293-016-0104-8

113. Mahmoodzadeh S, Dworatzek E. The role of 17beta-estradiol and estrogen receptors in regulation of $\mathrm{Ca}(2+)$ channels and mitochondrial function in cardiomyocytes. Front Endocrinol. (2019) 10:310. doi: $10.3389 /$ fendo.2019.00310

114. Sickinghe AA, Korporaal SJA, den Ruijter HM, Kessler EL. Estrogen contributions to microvascular dysfunction evolving to heart failure with preserved ejection fraction. Front Endocrinol. (2019) 10:442. doi: 10.3389/fendo.2019.00442

115. Ventura-Clapier R, Piquereau J, Veksler V, Garnier A. Estrogens, estrogen receptors effects on cardiac and skeletal muscle mitochondria. Front Endocrinol. (2019) 10:557. doi: 10.3389/fendo.2019.00557

116. Zhang B, Miller VM, Miller JD. Influences of sex and estrogen in arterial and valvular calcification. Front Endocrinol. (2019) 10:622. doi: 10.3389/fendo.2019.00622

117. Kararigas G, Fliegner D, Forler S, Klein O, Schubert C, Gustafsson JA, et al. Comparative proteomic analysis reveals sex and estrogen receptor beta effects in the pressure overloaded heart. J Proteome Res. (2014) 13:5829-36. doi: $10.1021 /$ pr500749j

118. Kararigas G, Fliegner D, Gustafsson JA, Regitz-Zagrosek V. Role of the estrogen/estrogen-receptor-beta axis in the genomic response to pressure overload-induced hypertrophy. Physiol Genomics. (2011) 43:43846. doi: 10.1152/physiolgenomics.00199.2010

119. Kararigas G, Nguyen BT, Jarry H. Estrogen modulates cardiac growth through an estrogen receptor alpha-dependent mechanism in healthy ovariectomized mice. Mol Cell Endocrinol. (2014) 382:909-14. doi: 10.1016/j.mce.2013.11.011

120. Kararigas G, Nguyen BT, Zelarayan LC, Hassenpflug M, Toischer K, Sanchez-Ruderisch H, et al. Genetic background defines the regulation of postnatal cardiac growth by 17beta-estradiol through a beta-catenin mechanism. Endocrinology. (2014) 155:2667-76. doi: 10.1210/en.20132180

121. Sanchez-Ruderisch H, Queiros AM, Fliegner D, Eschen C, Kararigas G, Regitz-Zagrosek V. Sex-specific regulation of cardiac microRNAs targeting mitochondrial proteins in pressure overload. Biol Sex Differ. (2019) 10:8. doi: 10.1186/s13293-019-0222-1

122. Duft K, Schanz M, Pham H, Abdelwahab A, Schriever C, Kararigas G, et al. 17beta-Estradiol-induced interaction of estrogen receptor alpha and human atrial essential myosin light chain modulates cardiac contractile function. Basic Res Cardiol. (2017) 112:1. doi: 10.1007/s00395-016-0590-1

123. Lai S, Collins BC, Colson BA, Kararigas G, Lowe DA. Estradiol modulates myosin regulatory light chain phosphorylation and contractility in skeletal muscle of female mice. Am J Physiol Endocrinol Metab. (2016) 310:E724-33. doi: 10.1152/ajpendo.00439.2015

124. Mahmoodzadeh S, Pham TH, Kuehne A, Fielitz B, Dworatzek E, Kararigas G, et al. 17beta-Estradiol-induced interaction of ERalpha with NPPA regulates gene expression in cardiomyocytes. Cardiovasc Res. (2012) 96:411-21. doi: $10.1093 / \mathrm{cvr} / \mathrm{cvs} 281$

125. Nguyen BT, Kararigas G, Jarry H. Dose-dependent effects of a genisteinenriched diet in the heart of ovariectomized mice. Genes Nutr. (2012) 8:383-90. doi: 10.1007/s12263-012-0323-5

126. Nguyen BT, Kararigas G, Wuttke W, Jarry H. Long-term treatment of ovariectomized mice with estradiol or phytoestrogens as a new model to study the role of estrogenic substances in the heart. Planta Med. (2012) 78:6-11. doi: 10.1055/s-0031-1280228
127. Kararigas G, Becher E, Mahmoodzadeh S, Knosalla C, Hetzer R, RegitzZagrosek V. Sex-specific modification of progesterone receptor expression by 17 beta-oestradiol in human cardiac tissues. Biol Sex Differ. (2010) 1:2. doi: 10.1186/2042-6410-1-2

128. Kararigas G, Bito V, Tinel H, Becher E, Baczko I, Knosalla C, et al. Transcriptome characterization of estrogen-treated human myocardium identifies Myosin regulatory light chain interacting protein as a sex-specific element influencing contractile function. J Am Coll Cardiol. (2012) 59:410-7. doi: 10.1016/j.jacc.2011.09.054

129. Hein S, Hassel D, Kararigas G. The zebrafish (Danio rerio) is a relevant model for studying sex-specific effects of 17beta-estradiol in the adult heart. Int $J$ Mol Sci. (2019) 20:6287. doi: 10.3390/ijms20246287

130. Fliegner D, Schubert C, Penkalla A, Witt H, Kararigas G, Dworatzek E, et al. Female sex and estrogen receptor-beta attenuate cardiac remodeling and apoptosis in pressure overload. Am J Physiol Regul Integr Comp Physiol. (2010) 298:R1597-606. doi: 10.1152/ajpregu.00825.2009

131. Queiros AM, Eschen C, Fliegner D, Kararigas G, Dworatzek E, Westphal $C$, et al. Sex- and estrogen-dependent regulation of a miRNA network in the healthy and hypertrophied heart. Int J Cardiol. (2013) 169:331-8. doi: 10.1016/j.ijcard.2013.09.002

132. Kararigas G. Oestrogenic contribution to sex-biased left ventricular remodelling: the male implication. Int J Cardiol. (2021) 343:83-4. doi: 10.1016/j.ijcard.2021.09.020

133. Liu Y, Yao Y, Li H, Qiao F, Wu J, Du ZY, et al. Influence of endogenous and exogenous estrogenic endocrine on intestinal microbiota in zebrafish. PLoS One. (2016) 11:e0163895. doi: 10.1371/journal.pone.0 163895

134. Lindheim L, Bashir M, Munzker J, Trummer C, Zachhuber V, Leber B, et al. Alterations in gut microbiome composition and barrier function are associated with reproductive and metabolic defects in women with polycystic ovary syndrome (PCOS): a pilot study. PLoS One. (2017) 12:e0168390. doi: 10.1371 /journal.pone. 0168390

135. Liu R, Zhang C, Shi Y, Zhang F, Li L, Wang X, et al. Dysbiosis of gut microbiota associated with clinical parameters in polycystic ovary syndrome. Front Microbiol. (2017) 8:324. doi: 10.3389/fmicb.2017. 00324

136. Torres PJ, Siakowska M, Banaszewska B, Pawelczyk L, Duleba AJ, Kelley ST, et al. Gut microbial diversity in women with polycystic ovary syndrome correlates with hyperandrogenism. J Clin Endocrinol Metab. (2018) 103:1502-11. doi: 10.1210/jc.2017-02153

137. Insenser M, Murri M, Del Campo R, Martinez-Garcia MA, FernandezDuran E, Escobar-Morreale HF. Gut microbiota and the polycystic ovary syndrome: influence of sex, sex hormones, and obesity. J Clin Endocrinol Metab. (2018) 103:2552-62. doi: 10.1210/jc.201 7-02799

138. Harada N, Hanaoka R, Horiuchi H, Kitakaze T, Mitani T, Inui H, et al. Castration influences intestinal microflora and induces abdominal obesity in high-fat diet-fed mice. Sci Rep. (2016) 6:23001. doi: 10.1038/srep23001

139. Arumugam M, Raes J, Pelletier E, Le Paslier D, Yamada T, Mende DR, et al. Enterotypes of the human gut microbiome. Nature. (2011) 473:174-80. doi: 10.1038/nature09944

140. Kararigas G, Seeland U, Barcena de Arellano ML, Dworatzek E, Regitz-Zagrosek V. Why the study of the effects of biological sex is important. Commentary. Ann Ist Super Sanita. (2016) 52:149-50. doi: 10.4415/ANN_16_02_03

141. Chen PB, Black AS, Sobel AL, Zhao Y, Mukherjee P, Molparia B, et al. Directed remodeling of the mouse gut microbiome inhibits the development of atherosclerosis. Nat Biotechnol. (2020) 38:1288-97. doi: 10.1038/s41587-020-0549-5

142. Tariq R, Saha S, Furqan F, Hassett L, Pardi D, Khanna S. Prevalence and mortality of COVID-19 patients with gastrointestinal symptoms: a systematic review and meta-analysis. Mayo Clin Proc. (2020) 95:1632-48. doi: 10.1016/j.mayocp.2020.06.003

143. Sultan S, Altayar O, Siddique SM, Davitkov P, Feuerstein JD, Lim JK, et al. AGA institute rapid review of the gastrointestinal and liver manifestations of COVID-19, meta-analysis of international data, and recommendations for the consultative management of patients with COVID-19. Gastroenterology. (2020) 159:320-34 e27. doi: 10.1053/j.gastro.2020.05.001 
144. Hoffmann M, Kleine-Weber H, Schroeder S, Kruger N, Herrler T, Erichsen $\mathrm{S}$, et al. SARS-CoV-2 cell entry depends on ACE2 and TMPRSS2 and is blocked by a clinically proven protease inhibitor. Cell. (2020) 181:271-80 e8. doi: 10.1016/j.cell.2020.02.052

145. Ritter O, Kararigas G. Sex-biased vulnerability of the heart to COVID-19. Mayo Clin Proc. (2020) 95:2332-5. doi: 10.1016/j.mayocp.2020.09.017

146. Kararigas G. Sex-biased mechanisms of cardiovascular complications in COVID-19. Physiol Rev. (2022) 102:333-7. doi: 10.1152/physrev.0002 9.2021

Conflict of Interest: The authors declare that the research was conducted in the absence of any commercial or financial relationships that could be construed as a potential conflict of interest.
Publisher's Note: All claims expressed in this article are solely those of the authors and do not necessarily represent those of their affiliated organizations, or those of the publisher, the editors and the reviewers. Any product that may be evaluated in this article, or claim that may be made by its manufacturer, is not guaranteed or endorsed by the publisher.

Copyright () 2022 Li and Kararigas. This is an open-access article distributed under the terms of the Creative Commons Attribution License (CC BY). The use, distribution or reproduction in other forums is permitted, provided the original author(s) and the copyright owner(s) are credited and that the original publication in this journal is cited, in accordance with accepted academic practice. No use, distribution or reproduction is permitted which does not comply with these terms. 